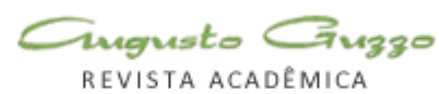

\title{
O professor universitário em sala de aula
}

\author{
Márcio Magera e Joelma T. P. Conceição² \\ Recebido em: 13/11/2014. Aprovado em: 01/12/2014. Disponibilizado em: 26/12/2014 \\ 1. Márcio Magera é P.hD, Pós Doutorado em Administração pela FUC USA. Doutor em Sociologia e Pós Doutorado em Sociologia \\ pela Unicamp e Doutor em Administração pela FCU USA. Tel 11997624781. \\ 2. Joelma T. P. Conceição é Mestre em Administração e Profa na FACCAMP.
}

\section{Resumo}

O presente artigo trata da (r)evolução ocorrida no processo ensino-aprendizagem a partir da introdução das mídias eletrônicas em sala de aula e das redes sociais presentes no dia a dia, tanto dos alunos como dos professores, que tiveram de se adequar a essas tecnologias. $\mathrm{O}$ ambiente escolar traduz-se como agente de mudanças sociais, políticas e econômicas de um país, e os modelos educativos são desenvolvidos com base nos comportamentos modelados e reforçados. O professor, aplicador do programa educacional, tem como o objetivo desenvolver competências e habilidades, formando o perfil do egresso desejado do curso.

Palavras-chave: didática; ensino; tecnologia digital

\begin{abstract}
This article deals with the (r)evolution occurred on teaching-learning process from the introduction of electronic media in the classroom and social networks present in everyday, both students and teachers, who had to adapt to these technologies. The school environment is reflected as social, political and economic agent of conditions in a country, and educational models are developed on modeled basis and reinforced behavior. Teacher, who is the educational program applicator, has as objective to develop skills and abilities, forming the profile of the desired course egress.
\end{abstract}

Keywords: teaching, education, digital technology. 


\section{Introdução}

O objetivo de se tratar da (r)evolução ocorrida no processo ensino-aprendizagem a partir da introdução das mídias eletrônicas em sala de aula é compreender a adaptação dos alunos e da própria escola a esse processo.

No Brasil a oferta de ensino superior se alterou significativamente a partir da década de 90, especificamente 1996 quando o MEC - Ministério da Educação e Cultura autorizou a abertura de novos cursos pelas escolas particulares e a promoção dessas à Universidade. Registramos a universalização do ensino, mas, continuamos a usar os mesmos métodos de ensino do passado, substituindo a qualidade pela quantidade. Um novo olhar se faz necessário sobre a prática do ensino superior na contemporaneidade, em que o uso da tecnologia como instrumento de ensino e aprendizagem, tem se intensificado nas principais universidades do mundo, provocando uma mudança no cenário internacional da oferta do ensino superior. No Brasil, particularmente, o mercado vem dando o tom das mudanças. Existe uma nova geração chegando às faculdades que pode ser chamada de $y, z$ ou simplesmente "geração facebook", que não atende o modelo antigo de ensinoaprendizagem. Esta geração, estimada em 42 milhões, com idade entre 18 e 30 anos, movimenta 506 bilhões de reais por ano (Instituto Data Popular, 2013) e está provocando insegurança nos professores, que até pouco tempo atrás ainda usavam retroprojetor, giz e lousa.

Segundo o MEC - Ministério da Educação e Cultura, mais de 40\% dos professores do ensino superior no Brasil não utilizam o computador como instrumento de uso diário, nem como recurso didático em sala de aula. O governo vem incentivando o uso de tecnologias no ensino amparado pela Lei de Diretrizes e Bases da Educação
Nacional (art. 36 da LDB n. 9.394/96). Há orientação do MEC para que se utilize a Educação a Distância (EAD), no ensino superior, além da utilização das Tecnologias de Informação e Comunicação (TIC), em cursos totalmente virtuais na graduação (Decreto Fed. 5.622/05, que normatiza o art. 80 da LDB) ou em disciplinas denominadas "semipresenciais", por utilizarem parte presencial e parte à distância em seus currículos (Portaria MEC 4.059/04). As IES - Instituto de Ensino Superior podem utilizar até $20 \%$ da carga horária em aulas semipresenciais, mas, a adesão às indicações do MEC ainda são tímidas e $80 \%$ das IESs continuam atuando no modelo do século passado, como se nada tivesse mudado no cenário do ensino

\section{O aluno digital}

$\mathrm{Na}$ atualidade existe o aluno digital que em uma escola analógica, representa um paradoxo para a Escola Nova, que desde o início do século XX tinha a pretensão de ser um movimento de renovação pedagógica e fundamentalmente técnico. A política educacional brasileira não vem obtendo sucesso na melhoria da qualidade de ensino. Apesar de termos hoje 19\% dos jovens entre 18 e 25 anos cursando o ensino superior, número que supera em $40 \%$ a década passada, com esta marca o Brasil fica longe dos países em desenvolvimentos como Chile com 45\%, Coreia do Sul com 69\% (PNAD, 2009). Portanto, eis o cenário desafiador para o professor: $O$ aprendizado necessita de novas dimensões no que diz respeito à ciência da educação e a arte de ensinar. A profissão de professor não pode ser considerada como um mero complemento de salário, ou como salientou Freire:

"A educação como prática da liberdade, ao contrário daquela que é prática da dominação, implica a negação do homem abstrato, isolado, solto, desligado do mundo, assim como também a negação do mundo como 
uma realidade ausente dos homens" (FREIRE, 2001, p.70).

Este novo aluno, digital, sabe usar muito bem as novas tecnologias, mas tem dificuldades para entender um texto, desenvolver um raciocínio matemático ou dirigir sua própria vida, e tem o gozo e a liberdade como parâmetros de verdade, proposto, muitas vezes pela mídia. Em um contexto socrático pode-se dizer que "A busca contínua de prazeres destrói seu próprio gozo. A alma que o faz perde sua liberdade interior e se torna escrava das paixões e das solicitações do corpo, perdendo o domínio de si mesma" (1996, p.37).

Tendo assim um quadro não linear e um círculo em construção, o novo aluno e o novo professor, têm muitos desafios, entre eles, desconstruir as incertezas, cuja única certeza é a eterna dúvida do ensinar aprender. Usando uma licença poética: Que não deve ter modelos, caras, muros ou paredes, o ensino vem da alma para o coração.

Neste cenário de mudanças, as habilidades afetivas, retratando a taxonomia de Bloom, se fazem necessárias, visto que o modo de agir do professor em sala de aula fundamenta-se numa determinada concepção do papel do professor, que por sua vez reflete valores e padrões da sociedade. Como afirma Abreu:

"Já houve tempo em que as expectativas com relação ao papel do professor eram claras e homogêneas, definindo um padrão uniformizado de ação... hoje a ação do professor em sala de aula se tornem cada vez mais complexos e ambíguos" (1997, p.115).

Portanto, o próprio professor, na construção do saber, fica sem um direcionamento, um norte confiável no processo didático e metodológico e suas técnicas se esgotam diante de um universo heterogêneo e sem uma identidade definida.
É importante que o professor conheça seu aluno, crie uma empatia com seus valores, deixando claros seus objetivos com relação ao conteúdo programático daquela disciplina e destacando as habilidades e competências que o discente deverá adquirir com o processo de ensino aprendizagem. A aproximação com a realidade do aluno fará com que o professor adquira identidade no universo onde está inserido, e criará normas de conduta, diretrizes, tornando o processo de aprendizagem mais tranquilo e seguro para todos os envolvidos. Propor e ouvir temas sobre várias questões interdisciplinares criará mecanismos para destacar experiências práticas dos discentes, é necessário aproximar-se das suas histórias de vida, deixando a emoção dos envolvidos assumir a temática da aula e imaginando romper paredes físicas para que todos possam viajar no mundo novo do saber, ou como disserta Rubens Alves "A inteligência deseja viajar com leveza” (ALVES, 1995, p.18).

\section{O papel do professor}

No início do processo é importante que o professor defina uma proposta pedagógica e quais serão suas técnicas de aplicação do conhecimento, informação e como será a avaliação dos conteúdos ministrados, sem perder o compromisso com o tempo que faz de todos os homens escravos do relógio.

A didática é fundamental neste momento. O termo "didática" deriva do grego didaktiké, que significa "arte de ensinar", é o estudo do processo de ensinoaprendizagem em sala de aula e de seus resultados. Neste contexto, caberia ao professor incentivar, criar, propor orientar e organizar as situações de aprendizagem, adequando-as às capacidades e as características individuais dos alunos. Apresentar uma didática que alcance a todos na sala e formalizar um entendimento do discurso sem perder a emoção, o contato com 
o que é mais rico no ensino, o aprender com satisfação, amor e compreensão, obtidos pela motivação que é outro fator determinante no sucesso da aprendizagem dos alunos.

A motivação é o fator principal da ação, e tem origem numa necessidade, assim, à medida que o educando sente necessidade de aprender, tende a buscar fontes capazes de satisfazê-las, utilizando-se de leituras, pesquisas, aulas e discussões. Alunos motivados aprendem com mais facilidades e tornam o processo de ensino aprendizagem melhor e mais eficaz.

As habilidades cognitivas são importantes no processo de ensino aprendizagem. O professor obtém um melhor resultado no processo didático e metodológico da aplicação dos conteúdos programáticos da sua disciplina, aplicando a taxonomia de Bloom, que são classificadas em três áreas mutuamente exclusivas: a cognitiva, ligada ao saber; a afetiva ligada a sentimentos e posturas, trabalhada no item anterior; e a psicomotora, ligada às ações físicas. $\mathrm{s}$ teóricos pesquisadores do behaviorismo ou comportamentalistas dissertam que o conhecimento é resultado direto da experiência, portanto, o professor necessariamente precisa aplicar atividades que levem os alunos a criarem soluções, alternativas para problemas e até mesmo a geração de problemas para apresentarem soluções diante de desafios expostos.

A escola ainda é reconhecida como agente de mudanças sociais, políticas e econômicas de um país, e os modelos educativos são desenvolvidos com base nos comportamentos modelados e reforçados. $\mathrm{O}$ professor é visto como um aplicador do programa educacional, recebido (pronto) da IES, e cujo conteúdo, não pode ser alterado. $\mathrm{E}$, neste contexto, tem como o objetivo desenvolver competências e habilidades, formando assim o perfil do egresso desejado do curso. Mas, para Skinner, um dos principais teóricos desta abordagem, a realidade é um fenômeno objetivo, e o ser humano é um produto do meio, podendo, ser controlado e manipulado. Sendo assim, o aluno não participa das atividades relevantes com autonomia, e o processo molda o resultado, sem levar em consideração a parte mais importante que é a reconstrução do conhecimento como parte integradora do processo ensino aprendizagem.

Os humanistas têm como principal objetivo o desenvolvimento das personalidades individuais, entre eles, Carl Rogers como um de seus principais teóricos, disserta que o professor não transmite conteúdo, mas dá assistência aos estudantes, atuando como facilitador do processo. Assim, a ênfase é no aluno, dentro de um contexto macro ambiental, levando-se em consideração a individualidade e a autonomia como princípio do ensino aprendizagem. $\mathrm{O}$ processo de ensino que utiliza a cognição tem como principal ação a interação entre sujeito e objetivo. O Cognitivismo considera o indivíduo como um sistema aberto, que passa por estruturações sucessivas, em busca de um estágio final nunca alcançado completamente. O aluno utilizando uma de suas múltiplas inteligências poderá ter a oportunidade de aprender por si próprio.

\section{A estratégia do professor como facilitador}

A estratégia do processo seria facilitar ao aluno no desenvolvimento de um pensamento autônomo, crítico e criativo, criando assim, um ambiente de desafios constantes e motivacionais, evitando apresentar soluções prontas para os alunos. A avaliação deve acontecer valorizando as capacidades individuais e cognitivas dos alunos em um processo contínuo, e privilegiando as habilidades e competências do programa de ensino. 
O professor sendo um facilitador tem como missão fomentar entre os alunos da sala o interesse pelo debate, pela criação e pelo respeito mútuo. Utilizando desse processo acaba por promover as estratégias para facilitar os alunos ao alcance dos objetivos, como disserta Abreu:

"Alcance dos objetivos de
aprendizagem e não como fórmulas
fachadas, intocáveis, o professor pode
se inspirar nelas para criar as maneiras
de mais adequadas para sua classe, sua
disciplina, para si mesmo e para as
condições e que dispõe na sua escola"
(1997, p.61).

Para promover a interação o professor necessariamente precisa conhecer os objetivos do programa, estabelecer uma relação de feedback com a sala e promover a troca de saber entre os alunos, criando um network e levantando as principais dúvidas com os colegas de grupo, obtendo-se mais rápido a solução aos desafios propostos pelo professor. É papel também do professor a identificação de parâmetros, tópicos e ações comuns entre os alunos facilitando a interação e criação de uma identidade com foco no processo de ensino aprendizagem do grupo.

Os estudos da psicologia educacional forneceram diversas pesquisas pretendendo estabelecer relações entre as características do professor e a aprendizagem do aluno. O que determina o sucesso do processo e o melhor aproveitamento do aluno é justamente o relacionamento, a comunicação que o professor estabelece, criando um clima ou uma atmosfera adequada para ocorrer o ensinamento. É a atuação do professor que colabora para uma adequada aprendizagem. A comunicação poderá se dar sob vários aspectos, entre eles a utilização de e-mail, sites, telefone, chats, presencial, portanto, o professor deve utilizar-se da tecnologia da informação para chegar até ao aluno, utilizando uma comunicação clara e objetiva, sugerindo assim, que o aluno interaja durante todo o processo de ensino aprendizagem.

O professor precisa entender que a comunicação não se dará de maneira uniforme com todos, visto que o entendimento passa por uma construção do saber e que não temos na sala uma homogeneização de seres, e sim, indivíduos com características heterogêneas, cuja formação social e política dará o suporte para o entendimento da comunicação. Portanto, este processo deve ser elaborado pensando no universo a ser atingido e quais os objetivos pretendidos pelo professor, aplicando-se ferramentas que facilitem e ampliem a comunicação com seus alunos. Importante também verificar se há na sala alunos portadores de necessidades especiais, os quais deverão ter a inclusão no processo.

As avaliações não devem ser tratadas como instrumento para medir a inteligência dos alunos. Professor e aluno estão empenhados em construir uma aprendizagem e neste processo é imprescindível que ambos possam contar com um conjunto de dados e informações que lhes digam se a aprendizagem está sendo conseguida. Este mecanismo deverá acontecer normalmente, através de técnicas pedagógicas aplicadas em ações que sinalizem e indiquem as competências e habilidades projetadas no programa da disciplina. Mas é importante que o docente entenda que existem as múltiplas inteligências e que os alunos não são iguais, visto serem cidadãos sociais e terem suas origens sob diversos aspectos, dentre eles o econômico, o político e o social, que influenciam no processo de ensino aprendizagem. Sendo assim, caberá apresentar análises interdisciplinares com objetivos de identificar as múltiplas inteligências e dar enfoque ao processo diante de tais variáveis. 


\section{Considerações finais}

Concluir, o que não se pode concluir terminar o que não tem começo, medir o que não para de se mover, pintar o que não tem cor, eis os grandes desafios do educador neste início de século XXI. Atuar em sala de aula, hoje, exige uma carga de preparação técnica e emocional. O professor precisa entender que ele está no mesmo rio que os alunos, e suas incertezas são iguais, e que juntos deverão construir uma simbiose que os tornarão um só! Sim, o professor precisa conquistar a sala, identificar sua heterogeneidade social, política e econômica, traduzir as diferenças pela aceitação, compreensão e desafios.

Através de um processo metodológico, com práticas de pedagogia e didática, traçar um planejamento de aula, com objetivos, justificativas, conteúdo programático, referencial teórico e, com isso, sinalizar um método para medir os objetivos. Com isso, o professor não morrerá jamais, ao formar cidadãos éticos e detentores de conhecimento, trará uma cidadania social e, sempre será lembrado pelos quais ele ajudou a construir um pensamento de reflexão. Possibilitar aos alunos, conhecimento para criação e análise, potencial para ver o mundo pelo seu próprio olhar, desenvolvendo capacidade de criticar e construir a sua realidade, a partir de sua individualidade. Eis, a missão do mestre!

\section{Bibliografia}

1. Abreu, Maria Celia e Marcos Tarciso Masetto. O professor Universitário em aula. Editora Mg editores associados, SP, 1997.

2. Alves. Rubens. Estórias de quem gosta de ensinar. Editora Epeculum, SP, 1995.

3. Eco, Umberto. Como se faz uma tese. Editora Perspectiva. SP, 1991.

4. Freire Paulo. Pedagogia do oprimido. Editora Paz e Terra, RJ. 2001.

6. Ramos, Maria Beatriz. Aprender e Ensinar Diferentes Olhares e Práticas. RS, Edipurgs, 2011.

7. Socrates. Vida e pensamentos. Editora Martin Mclaret, SP, 1996.

http://meuartigo.brasilescola.com/educacao /a-eficacia-didatica-ensino-superior.htm, acesso em 9 de outubro de 2013.

http://revistaescola.abril.com.br/historia/pr atica-pedagogica/skinner-428143.shtml, acesso em 4 de outubro de 2013. Biblioteca do sistema moodle da FVG. 2013. 